\title{
AS GEOGRAFIAS DO EXÍLIO: LUGARES DO CORPO E DA MEMÓRIA NO CONTO DE MARIO BENEDETTI
}

\section{THE GEOGRAPHIES OF THE EXILE: PLACES OF THE BODY AND MEMORY IN THE TALE OF MARIO BENEDETTI}

CERVO, Juliana Milman ${ }^{1}$

RESUMO: O presente trabalho propõe-se a analisar o conto Geografias, do escritor uruguaio Mario Benedetti, a partir da compreensão de que existe sempre uma dimensão da alteridade radical que nos escapa ao nos depararmos com uma literatura acerca do exílio e da tortura. Os personagens do conto se ancoram em lugares da memória, conceito proposto por Pierre Nora (1993), em razão da dificuldade de acederem às suas recordações. O trauma experimentado por sua condição de exilados rompe com o acesso ao simbólico, e todas as marcas ficam restritas ao corpo. Essa escrita visa a compreender como a obra de Benedetti irá contribuir para a garantia de um ethos enunciativo diante das geografias dos corpos talhados pela violência de Estado, até então sem direito à fala, a partir da possibilidade de transmutação da dor vivida em escrita criativa.

PALAVRAS-CHAVE: Memória, exílio, corpo, trauma.

\begin{abstract}
The present work proposes to analyze the story Geographies, by the uruguayan writer Mario Benedetti, from the understanding that there is always a dimension of radical alterity that escapes us when we come across a literature on exile and torture. The characters of the tale are anchored in places of memory, a concept proposed by Pierre Nora (1993), because of the difficulty of accessing their memories. The trauma experienced by his status as exiles
\end{abstract}

\footnotetext{
${ }^{1}$ Mestranda em Escrita Criativa pela Pontifícia Universidade Católica do Rio Grande do Sul. Graduada em Psicologia pela Universidade Federal do Rio Grande do Sul.
} 
breaks with access to the symbolic, and all marks are restricted to the body. This writing aims to understand how the work of Benedetti will contribute to the guarantee of an enunciative ethos before the geographies of the bodies carved by state violence, hitherto without the right to speak, from the possibility of transmutation of pain lived in creative writing.

KEYWORDS : Memory, exile, body, trauma.

\section{Introdução: Mario Benedetti, um exilado}

Mario Benedetti nasceu em Paso de los Toros, no Uruguai, em 1920. Contudo, passou grande parte de sua vida em Montevidéu, cidade guardiã de sua memória. Explorou diversos gêneros literários, como a poesia, o conto, o romance e o ensaio. Integrou a Geração de 45, iniciando carreira literária em 1949. Em 1952, participou ativamente como militante de esquerda no movimento de oposição ao Tratado Militar com os Estados Unidos. Sua obra é vasta, destacando-se o livro de poesia Poemas de Oficina (1956), a partir do qual ficou conhecido enquanto escritor, e o romance A Trégua (1960). Com o Golpe de Estado de 1973, Benedetti exilou-se em alguns países. Morou na Argentina, no Peru, em Cuba e em Madrid. Seu retorno ao Uruguai ocorreu em 1983, período de "desexílio" que marcou a continuidade de sua obra literária. Faleceu em 2009, em sua Montevidéu, com 88 anos.

Durante a época em que passou na Espanha, Benedetti escreveu Geografias (2009), conjunto de 14 contos que discorrem sobre o exílio. O presente trabalho propõe-se a analisar o conto de mesmo nome da obra, Geografias, que aborda as distâncias incuráveis dos espaços urbanos. Dos espaços temporais. Dos espaços do corpo. Espaços pulverizados após longos anos de ditadura militar uruguaia e do exílio experimentado por seus personagens. Lugares de uma memória desamparada pela dor.

Segundo Said (2003), o exílio pode ser pensado como fratura incurável entre o ser e o seu lugar natal. Como um estado de descontinuidade, que se diferencia da condição dos refugiados e dos emigrantes em função de ser uma prática de banimento. Contudo, Said (2003) questiona a razão pela qual o exílio fora tão facilmente assimilado pela cultura moderna, uma vez que este revela uma condição devastadora de perda e de solidão. Dentre os possíveis motivos, o autor afirma que há um gênero da literatura ocidental do século XX que é 


\section{1 sanganda}

extraterritorial, feito por exilados e sobre exilados. Porém, é fundamental que se tenha o cuidado de não reduzir o sofrimento daqueles que vivenciaram o exílio como algo benéfico e enriquecedor para a literatura, deixando-se de considerar suas mutilações. Desse modo, buscamos analisar os recursos narrativos que possibilitam uma ética enunciativa, um cuidado e uma sensibilidade com a qual Benedetti costura a experiência à trama da ficção.

\section{Ficções Mistas e Autoficção: um meio de legitimar a dor do outro?}

Said (2003) afirma que, "para tratar o exílio como uma punição política contemporânea, é preciso mapear territórios de experiências que se situam além daqueles cartografados pela própria literatura do exílio" (Said, 2003, p. 48). Assim, haveria um comprometimento ético que ultrapassaria o domínio da literatura e incidiria no real, naquele campo da experiência incomunicável.

Contudo, segundo Graziadei (2015), a literatura pode expor o não dito de uma época, através da transformação de uma experiência vivida em narrativa criativa. As histórias de exílio escritas por Benedetti contêm um viés autoficcional, em que o autor consegue ressignificar fatos históricos, verídicos, a partir de personagens e de enredo fictícios. Benedetti é, então, testemunha e também protagonista de sua obra, lançando mão de vestígios de sua memória para elaborar um passado e constituir um futuro. E a autobiografia, na pós-modernidade, passa a ser pensada "como ficção de acontecimentos reais" (Graziadei, 2015, p. 57).

Em consonância a essa ideia, Krysinski (2003) cita Baudrillard e Guillaume para explicar o conceito de ficções mistas, as quais seriam "qualquer coisa que é construída a partir de um real que, em seguida, é estimulado de certa quantidade de imaginário, de ficção" (Guillaume, Baudrillard, 1994 apud Krysinski, 2003, p. 34). Segundo tais autores, as ficções mistas são os meios a partir dos quais podemos lutar contra a raridade do outro, a raridade da alteridade em nossa sociedade. Krysinski (2003) discorre sobre a escrita de viagem enquanto operador cognitivo, em que o sentido da alteridade deve ser extraído de construções narrativas e discursivas complexas, em um jogo relacional. Desse modo, as ficções mistas revelariam uma dimensão da alteridade radical, aquela jamais apreensível, jamais acessível ao outro. A obra de Benedetti pode ser compreendida, portanto, como uma ficção mista capaz de produzir um entendimento da alteridade, da dor emudecida que ganha potência a partir da possibilidade de escrita e de retranscrição das marcas traumáticas. 


\section{Geografias: lugares da memória e do corpo}

Esse conto é narrado em primeira pessoa por Roberto, um exilado uruguaio, que primeiro residiu em Buenos Aires - assim como Benedetti -, e que atualmente mora em Paris. Ele e Bernardo, outro exilado uruguaio, estão no café Cluny. Ambos buscam recuperar a imagem da cidade de sua memória desvanecida: Montevidéu, cristalizada como algo sagrado em meio ao afastamento de ambos. Desenvolveram um jogo lúdico, um jogo de memória, no qual almejam resgatar os detalhes da cidade longínqua:

Pavadas que uno inventa en el exílio para de algún modo convencerse de que no se está quedando sin paisage, sin gente, sin cielo, sin país (...) Es así: uno de los dos pregunta sobre un detalle (no privado, sino público) de la lejanísima Montevideo: un edificio, un teatro, un árbol, un pájaro, una actriz, un café, un político proscripto, un general retirado, una panadería, cualquier cosa. $\mathrm{Y}$ el outro tiene que describir ese detalle, tiene que exprimir al máximo su memoria para extraer de ella su postalita de hace diez años, o darse por vencido e admitir que no recuerda nada, que aquella figura o aquel dato se borraron, no se alojan más en su archivo mnemônico (p. 367)

É interessante ressaltar que o detalhe recuperado pelos personagens deve ser público, e não privado, aludindo ao que Zilá Bernd (2013) versa ao discutir Maurice Halbwachs e a dimensão da memória coletiva. Segundo a autora, "experiências mnemônicas, mesmo que vividas individualmente, como uma visita que fazemos pela primeira vez a uma determinada cidade, são coletivas na medida em que a experiência de outras pessoas participa desse encontro" (Bernd, 2013, p.29). Nesse sentido, a possibilidade de compartilhamento da memória é crucial para que o sujeito se aproprie de sua narrativa e de sua história. Além disso, a recuperação dessas memórias coletivas estará sempre atrelada aos lugares em que foram gestadas, pois "não há memória coletiva que não aconteça em um contexto espacial" (Halbwachs, 2006 apud. Bernd, 2013, p. 32)

Bernd (2013) retoma também Freud para refletir sobre a potência da memória enquanto relação, uma vez que se funda no contato com o outro. Assmann (2011) dialoga com essa perspectiva ao pontuar que o trauma será sempre uma ferida coletiva. No começo da história da psicanálise, o trauma era abordado predominantemente de forma individualizada, enquanto patologia do sujeito. Contudo, ao longo dos anos, passou a ser pensado frente à questão da 


\section{1 jangada}

violência de Estado, encontrando-se também no âmbito social e político. Os dois personagens de Benedetti são costurados, assim, de forma delicada, uma vez que ancoram seus esquecimentos individuais um no outro, buscando encontrar vestígios de um passado banido de seu presente a partir do que têm em comum: a vivência do exílio, imposição traumática.

No conto, o personagem que não se recorda de nada perde um ponto diante da resposta correta do outro que lembra. Porém, se tal resposta não satisfaz o perdedor, o ponto fica em suspensão até que o detalhe seja comprovado por uma fotografia, por exemplo. Segundo Assmann (2011), a imagem, assim como a escrita, é metáfora e medium de memória. A fotografia é considerada o mais forte indício de um passado que não mais existe, preservando, desse momento pretérito, um vestígio do real com o qual o presente está ligado por contato. Ela supera os demais media da memória por sua possibilidade de comprovação, contudo, sua memória "assume vida própria como recordação fantasmagórica" (Assmann, 2011, p. 238). A fotografia suprime a fala. Diante do impedimento de os dois personagens de serem sujeitos do discurso, ambos recorrem a esse suporte. Assmann (2011) também ressalta certos espaços como metáforas mnemônicas, tais como prédios que são símbolos de memória, os quais Bernardo e Roberto buscam retomar para reconstituir Montevidéu.

Pierre Nora (1993) formula o conceito "lugares de memória", que seriam, por exemplo - museus, arquivos, cemitérios, coleções, festas, aniversários, tratados, processos verbais, monumentos, santuários. Contudo, só serão lugares de memória aqueles que forem investidos de uma aura simbólica, de uma significação. Eles necessitam de intenção, de vontade de rememoração. Caso contrário, serão apenas lugares da história. O autor afirma que tais locais só existem por não haverem mais meios possíveis de recordação, e pontua: "se habitássemos ainda a nossa memória, não teríamos necessidade de lhe consagrar lugares” (Nora, 1993, p. 8) Desse modo, quanto menos a acessamos em seu interior, mais iremos requerer suportes externos e tangíveis nos quais buscar amparo. Nossa vivência subjetiva da lembrança passa a ser obliterada por uma "memória prótese" (Nora, 1993, p. 16). De acordo com Nora (1993), quando há distância, mediação, já estamos dentro da história, e não mais no âmbito da verdadeira memória.

Através dessa noção, podemos inferir que os personagens de Benedetti expõem com sensibilidade a limitação de se experimentar verdadeiramente as recordações, diante da condição impactante de exilados. Eles necessitam enraizar-se no concreto, em um espaço bruto. Assim, segundo Nora (1993), “o que nós chamamos de memória é, de fato, a constituição gigantesca e vertiginosa do estoque material daquilo que nos é impossível lembrar" (Nora, 


\section{1 jangada}

1993, p. 15). O que está no cerne desses lugares é exatamente "um jogo da memória e da história" (Nora, 1993, p. 22), exercício de interrogação sobre a própria memória que Bernardo e Roberto realizam com perseverança e nostalgia.

Na sequência do conto, há um ponto de virada chave: a presença de Delia, um antigo romance de Roberto que fora deixado no passado em função das circunstâncias políticas. Do café Cluny, Roberto reconhece a moça na parada de ônibus, esperando a luz verde. Lembra que faz oito ou nove anos que não a vê. Ele é tomado por uma onda de associações mnemônicas: os encontros, os beijos dos dois enamorados. Ele estava no segundo ano de engenharia na época. Ela, no primeiro ano do mesmo curso. Aos poucos, a dificuldade de se verem aumentou em função das demandas da militância. Ambos estavam sobrecarregados, tomados pelos ânimos aquecidos frente ao golpe militar. Até que Roberto se exilou em Buenos Aires, onde ficou sabendo que ela fora presa. O apelo espacial do conto ganha intensidade com a chegada de Delia, cujo corpo é descrito inicialmente quando ela, ao avistá-los: "abre la boca para um grito que no sale" (Benedetti, 2009, p. 368). Esse grito sufocado parece introduzir o leitor ao silêncio de Delia frente à violência sofrida enquanto esteve presa. Ao sentar-se junto aos amigos, Delia conta que a oposição está crescendo no Uruguai, que as pessoas estão perdendo o medo. Porém, quando eles lhe explicam o seu jogo de memória cotidiano, ela adverte:

Pero creo que ustedes no reconocerían la ciudad. Esse juego de las geografias perderían los dos. Por ejemplo? Dieciocho de Julio ya no tiene árboles, lo sabían? Ah. De pronto advierto que los árbores de Dieciocho eran importantes, casi decisivos para mí. Es a mí al que han mutilado. Me he quedado sin ramas, sin brazos, sin hojas. Insensiblemente, el juego de las geografías se transforma en una ansiosa indagación, Empezamos a repasar la ciudad, la nuestra, la mía y de Bernardo, con preguntas acuciosas. A Bernardo se le ocurre preguntar por La Plata. Uy, qué antigüedad, dice Delia. La echaron abajo, ahí está ahora el Banco Real, um edificio moderno, bastante lindo, pletórico de cristales. (p.

O Teatro Artigas também se acabou: agora é um estacionamento, um parking. Bernardo lembra-se da época de ouro em que lá assistia ao cinema pornô. Roberto se recorda da noite em que Michellini ali pronunciou um discurso e das histórias que seu pai, elo de memória transgeracional, lhe contava sobre os artistas que, no passado, apresentaram-se no teatro. A nostalgia parece devastar os dois personagens. De acordo com Graziadei (2015), “o exílio, um 


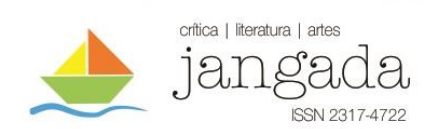

não-lugar por definição, se torna o lugar de memória no qual Montevidéu é uma lembrança invocada que se confronta com a realidade dos exilados" (Graziadei, 2015, p. 125).

Delia relata que agora, por todo lado, há andaimes de obras suspensas ou escombros. De acordo com Pierre Nora (1993), os lugares de memória evidenciam que o passado é radicalmente outro, impenetrável, "ele é esse mundo do qual estamos desligados para sempre" (Nora, 1993, p. 19). Tais locais são marcos testemunhas "das ilusões da eternidade" (Nora, 1993, p. 13), de modo que os sujeitos ancoram a suposta continuidade de sua história na ideia de que esses sítios vão durar para sempre, imutáveis. Contudo, o autor afirma: "se é verdade que a razão fundamental de ser um lugar de memória é parar o tempo, é bloquear o trabalho do esquecimento (...) os lugares da memória só vivem sua aptidão para a metamorfose”. (Nora, 1993, p. 32).

O espaço também se revela no corpo de Roberto - mutilado. Seu corpo é o meio afetado pelos âmbitos político e coletivo. Ele está tão pouco apropriado de sua narrativa, de sua memória, que tudo o que possui são lugares externos em que se apoiar. À medida que esses locais se modificam, o narrador fica completamente desamparado, tal é a fragilidade de sua identidade. Julia Kristeva (1994) discorre sobre a fragmentação do estrangeiro diante da condição de afastamento irremediável. Este traidor que trai a si mesmo tenta incorporar elementos da língua francesa, utilizando-se de palavras tais como passez pietons (Benedetti, 2009, p. 368), alsace, beaujolais (Benedetti, 2009, p. 367). Porém, segundo a autora, sua língua é o silêncio, mesmo estando rodeado de uma pluralidade idiomática. Ainda que o exilado busque desesperadamente sustentar-se em lugares de memória, ele exprime justamente esse não pertencimento a nenhum lugar e a nenhum tempo: "a origem perdida, o enraizamento impossível, a memória imergente, o presente em suspenso" (Kristeva, 1994, p. 15). O seu espaço será, portanto e paradoxalmente, “a própria transição que exclui a parada” (Kristeva, 1994, p. 15). E Kristeva (1994) questiona a existência desses sujeitos ao pontuar que "o estrangeiro não tem um si (...) meu eu está em outro lugar, meu eu não pertence a ninguém, meu eu não pertence a mim... eu existe? (Kristeva, 1994, p. 16)

Em sintonia a essa asserção, Ouellet (2013) discorre acerca de um estado de migrância identitária, de estesias da migração, a partir do qual o sujeito se perceberia inteiramente outro e se subtrairia a si próprio, por não conseguir se fundar, se constituir. De acordo com o autor, o reconhecimento das identidades implicaria a identificação de um tempo, de um lugar e de uma instância pessoal. "Alguém é porque ocupa tal espaço em tal momento" (Ouellet, 2013, p. 155). Em se tratando de narrativa, os personagens de Benedetti existiriam? O que legitimaria sua 


\section{1 jangada}

existência? Roberto parece revelar o vazio de um "não-sujeito", visto encontrar-se despedaçado ou fragmentado. Dessa forma, o "deslocado faz um buraco no tempo e no espaço" (Ouellet, 2013, p. 148), visto não haver território possível - mas abismo, precipício, num movimento de eterna fuga de si e de desenraizamento.

No conto, Roberto segue a discorrer sobre o corpo de Delia: "Y por primera vez su sonrisa (...) no me alegra la vida. Es como um gesto retroactivo. Como si le estuviera sonriendo no a alguien sino a algo" (Benedetti, 2009, p. 370). Roberto não se percebe como alguém aos olhos da amada, mas como coisa. É o desolamento de um estado de não-existência, perdido para sempre em um lugar que desconhece. O narrador tenta conectar-se à subjetividade dessa mulher enigmática, contudo, só consegue dela extrair uma limitação, uma impossibilidade tudo está restrito ao espaço corporal, ausente de fala e de significação:

su mano está sobre la mesita. Levemente tensa, aunque no crispada. Es el único sintoma de que no se siente en el mejor de los mundos. Qué puedo hacer sino mover mi mano hacia la suya y allí depositarla, simplesmente dejarla estar. (...) de pronto le han caído en el rostro como diez años, no con arrugas ni ojeras ni patas de gallo, sino con abatimiento y con tristeza. Y no con una tristeza del instante, provisional, efímera, sino otra incurable, atornillada a los huesos, con raíces en algún enigma que para ella no lo es. (p. 371)

Roberto a convida para ir até a casa dele. A distância até lá: seis quadras e meia. A distância entre eles: incontável, milhas e milhas os separam. Délia aceita. Lá, ambos conversam superficialmente sobre suas vidas atuais - ele é guarda noturno em um hotel parisiense; ela, tradutora, mas clandestina, porque sem residência. Em meio à pulverização de duas existências presas a um passado para sempre abolido, Roberto grita para si mesmo diante da incomunicabilidade de um diálogo que é silêncio: "la nostalgia como detergente, la nostalgia como corrosión, la nostalgia como consuelo" (Benedetti, 2009, p. 371). Os dois finalmente se abraçam, se beijam. Entretanto, ainda assim não estão próximos, e nem poderiam. Ele constata que Delia lança um olhar ao infinito - ela não está presente. Ante a quietação insuportável, o "silêncio espeso" (Benedetti, 2009, p. 372), Roberto colhe coragem para perguntar a Delia o que se passa, o que aconteceu com ela. Porém, não há palavras possíveis para exprimir a dor de uma experiência traumática:

Los ojos que me miran están secos. No puede ser, no va a ser, no hay regreso, entendes. Eso es lo que dice. (...) Todas las paisajes cambiaron, en todas partes 


\section{1 jangada}

hay andamios, em todas partes hay escombros. Mí geografía, Roberto. Mi geografía también há cambiado. Eso es lo que dice (p. 372).

Hillman (1993) busca reafirmar o vínculo entre cidade e alma, encadeando elementos pertencentes a ambas, tais como a reflexão, a profundidade, a possibilidade de promover encontros e de fortalecer relações humanas. Para o autor, a alma é a psique, o anima, tendendo a animar a vida da cidade e a fazê-la imaginar a partir de símbolos e de outros dispositivos imagéticos. Ele menciona as memórias emotivas que as cidades possuem, atentando também para a experiência emocional da tragédia:

Temos memórias emotivas em nossas cidades através de parques históricos, estátuas de personalidades, memoriais de guerra, a tradição dos fundadores. (...) A cidade, então, é uma história que se conta para nós à medida que caminhamos por ela. Significa alguma coisa, ela ecoa com a profundidade do passado. Há uma presença de história na cidade (p. 39).

Roberto acede a uma perspectiva de profundidade da cidade ao se referir aos matizes de iluminação como elemento subjetivo: "El verde esmeralda de la Vittel-Menthe confirma abusivamente la esperanza" (Benedetti, 2009, p. 370). Contudo, volta-se a uma esperança que é ilusão, visto que a mulher lhe introduz a geografias mudas, esburacadas. Geografias de desconsolo. De fim. Desse modo, ainda que ocorram encontros no café Cluny, que hajam espelhos para refletir as vidas, a Paris que Benedetti descreve está desalmada para os exilados. A própria Montevidéu se modificou a tal ponto que pertence a um não-lugar idílico e rarefeito. Pois as interações humanas não promovem um contato, apenas distância. E os lugares são antes da história, e não da lembrança.

O corpo de Délia é a metáfora das marcas mnemônicas impossíveis de serem retranscritas. Em oposição aos lugares da memória, fixados em superfícies e mediações tangíveis, a recordação é sempre fragmentada, assistemática, aleatória e incoerente. Segundo Assmann (2011), ela é "sempre descontínua e inclui necessariamente intervalos da não presença. Não se pode recordar alguma coisa que esteja presente. E para ser possível recordála, é preciso que ela desapareça temporariamente e se deposite em outro lugar, de onde se possa resgatá-la" (Assmann, 2011, p. 166). Assim, a recordação é vivida enquanto emaranhamento, enquanto mistério incompreensível. Delia está, portanto, presa à violência que sofrera para sempre presentificada no corpo. Ela não consegue dar sentido ao seu transbordamento de presença, ao seu congelamento no instante da tortura. A personagem é incapaz de modular 


\section{jan}

lembrança e esquecimento, o qual é fundamental para propiciar o acesso às palavras por ser "uma necessidade operacional da memória" (Bernd, 2013, p. 26).

Ao falar da escrita de viagem e do lugar do estrangeiro, Ianni (2000) percebe algo comum dos personagens desse tipo de narrativa - que o "recurso do eu para sair vencedor das aventuras é perder-se para se conservar, é a astúcia" (Ianni, 2000, p. 26). Nesse sentido, Delia perde-se de si mesma, de sua memória, para assim continuar vivendo. O contato com suas lembranças seria, para ela, da ordem do insuportável, visto que não consegue articular a intensidade presente no corpo e abrir espaço para o esquecimento que vem acompanhado da rememoração.

Assim como os lugares da memória se metamorfoseiam e excluem os sujeitos da apropriação de sua narrativa, o trauma opera uma cisão à dimensão simbólica. O indivíduo se reconhece radicalmente como outro, uma vez que não mais tem acesso às palavras. Nem sempre uma inscrição mnemônica vai ter representação. Nem sempre o sofrimento pode ser retranscrito e ressignificado. Existem marcas que comportam uma intensidade, um excesso, que não conseguem ser retraduzidas e recolocadas na experiência histórica do sujeito. Segundo Assmann (2011), Freud estabelece um paralelo entre o trabalho do escavador e do psicanalista, visto que este irá buscar reacessar memórias soterradas através de um minucioso trabalho de escavação de suas camadas. Almeja, portanto, conferir novos sentidos às lembranças adormecidas e reincorporá-las à compreensão que o sujeito tem de si e de sua narrativa.

$\mathrm{Na}$ cisão, os registros ficam no corpo, sem significação. Délia, por exemplo, não consegue encadear seu pensamento e comunicar a dor da tortura a Roberto. Por isso, faz-se crucial o trabalho dos escritores e dos psicanalistas. Esses assumem o papel de testemunho do testemunho, podendo, assim, suportar a escuta ou sustentar a escrita diante de uma vivência da ordem do incomunicável. A reparação é um compromisso político, do Estado, de reconhecer que houve uma perda. Contudo, ela pode ser estabelecida na singularidade de cada vivência traumática. O psicanalista, testemunhando o testemunho de quem fora torturado, vai emprestar significantes para auxiliar na reparação, de modo que as marcas da intensidade possam ser retranscritas ao sujeito e adquirir sentido. ${ }^{2}$

\footnotetext{
2 Anotações extraídas do quarto encontro "Clínicas do Testemunho", ciclo de palestras idealizado pelo Instituto Appoa e a Sigmund Freud Instituição Psicanalítica. O projeto é uma iniciativa também da Comissão de Anistia, criada pelo governo federal, de modo a capacitar psicólogos à escuta dos relatos daqueles que foram torturados e exilados no período da ditadura militar brasileira. Assim, visa a promover uma reparação dos direitos humanos aviltados, a nível coletivo e individual. A quarta conferência, intitulada "O que resta da ditadura?", ocorreu no dia 20/08/2016, com a psicanalista Bárbara Conte.
} 


\section{1 jangada}

Os escritores, tais quais os psicólogos, também podem viabilizar a criação de representação para aquilo que, até então, não possui mediação simbólica. A escrita de Benedetti possui uma riqueza e um cuidado ético ao revelar uma dimensão da alteridade radical, como fala Krysinksi (2003), uma vez que seus contos comportam o entendimento de que há sempre uma porção do outro que para nós é irredutível, uma verdadeira diferença que escapa a estereótipos e que nunca seremos capazes de desvelar. No máximo, conseguimos tocar e constatar nossa impotência diante de um universo que jamais compreenderemos, pois não experimentamos a tortura e o exílio em nossos corpos. É isso que Said (2003) escreve ao pontuar que o exílio não pode ser incorporado à literatura sem comprometimento ético, como algo que apenas rechearia o universo narrativo. Falar de exílio é falar, primordialmente, do indizível, do não sentido de uma alteridade radical que vai sempre nos exceder e nos escapar.

Benedetti atinge essa perspectiva com maestria em seu processo narrativo, talvez também por ancorar-se em sua própria experiência de exilado, permitindo que sua obra seja compreendida como autoficcional ou como ficção mista. Assim, consegue expor a complexidade da alteridade radical. Segundo Ouellet (2013), a alteridade não é apenas a presença do outro, mas, justamente, o lugar que escapa ao poder do ego - "do que ele experimenta na pura passividade, mesmo em sua relação com ele mesmo ou com seu corpo, que não são mais sentidos como o território exclusivo do próprio ou da identidade, mas como uma espécie de espaço fronteiriço" (Ouellet, 2013, p. 168). Diante do choque, do banimento, as geografias dos corpos estão absolutamente modificadas. São outras. Suas fronteiras estão borradas pelo excesso do impacto daquilo que é irreversível. E é isso, o trauma - é ferida em carne viva no corpo, pulsando e impedindo que o esquecimento cumpra sua função. Que a recordação consiga ser simbolizada e compartilhada. Fica-se preso para sempre no presente violento, sangra-se em vez de chorar.

\section{Considerações finais}

A partir da análise do conto Geografias, pudemos constatar o quanto o exílio produz marcas não apenas no que tange a um deslocamento espacial, mas também, subjetivo. Os corpos são afetados e passam a encenar um jogo de não pertencimento a nada, nem a ninguém. Benedetti constrói seus personagens de forma complexa e sensível, com cuidado quanto ao ethos 


\section{1 jangada}

enunciativo, ressignificando a dor da experiência concreta a partir da linha da escrita. Linha esta que almeja cicatrizar as feridas abertas. Roberto e Delia só existem enquanto fronteiras impermeáveis: a transformação que se operou é tão absoluta que ambos nunca mais se amarão como antes, passado perdido para sempre, memória desfalecida. A dimensão da alteridade radical é trabalhada nessa história com uma proeza que extrapola o sentido meramente literário, adentrando o leitor numa relação inter-humana. Através dessa escrita, compreendemos o que Kristeva quis dizer ao confessar que "o estrangeiro é um sonhador que faz amor com a própria ausência" (Kristeva, 1994, p.18). Um portador de um corpo-sombra que dificilmente se projeta. Contudo, o trabalho comprometido de Benedetti e de outros escritores possibilita a projeção desses corpos, garantindo-lhes contornos e inaugurando um acesso ao simbólico.

\section{REFERÊNCIAS BIBLIOGRÁFICAS}

ASSMANN, Aleida. Sobre as metáforas da recordação. In: ASSMANN, Aleida. Espaços da recordação: formas e transformações da memória cultural. Campinas: EDUNICAMP, 2011. BENEDETTI, Mario. Geografías. In: Cuentos Completos. Montevidéo: Editorial Planeta S.A., 2009.

BERND, Zilá. Estratégias memoriais na sociedade contemporânea. In: Por uma estética dos vestígios memoriais. Belo Horizonte: Fino Traço, 2013.

GRAZIADEI, Neiva Maria. Fronteiras da memória, o exílio de cada um: a narrativa dos rastros em Mario Benedetti e Marta Traba. 2015. 202 f. Tese (Doutorado em Letras) - Instituto de Letras, Universidade Federal do Rio Grande do Sul, Porto Alegre. 2001.

HILMANN, James. Cidade e Alma. In: Cidade \& Alma. São Paulo: Studio Nobel, 1993.

IANNI, Octavio. A metáfora da viagem. In: Enigmas da modernidade. Rio de Janeiro: Civilização Brasileira, 2000.

KRISTEVA, Julia. Tocata e fuga para o estrangeiro. In: Estrangeiros para nós mesmos. RJ: Rocco, 1994.

KRYSINSKI, Wladimir. Discurso de viagem e senso de alteridade. Organon, Porto Alegre, v. 17, n. 34, pp. 21-43, 2003.

NORA, Pierre. Entre memória e história: a problemática dos lugares. Projeto História. In: Revista do Programa de Estudos Pós-Graduados em História e do Departamento de História da PUC-SP, n. 10. São Paulo, dez.-1993.

OUELLET, Pierre. Palavras migratórias. As identidades migrantes: a paixão do outro. In: HANCIAU, Núbia \& DION, Syvia (Org.). A literatura na história. A história na literatura. Rio Grande: Ed. da FURG, 2013.

SAID, Edward. Reflexões sobre o exílio e outros ensaios. Tradução: Pedro Maia Soares. São Paulo: Companhia das Letras, 2003.

Sites consultados:

https://pt.wikipedia.org/wiki/Mario_Benedetti. Acesso em: 11/11/2016. 